\title{
Natural and technogenic geodynamic processes in the south ural
}

\author{
Maksim Nesterenko*, Aleksey Tsviak, and Vladimir Belov \\ Orenburg federal research center, Ural Branch of the Russian Academy of Sciences, Naberezhnaja \\ Str., 29, 460014 Orenburg, Russia
}

\begin{abstract}
In this paper is presented hydro-geodynamics and geodynamics in the South Urals. Seismicity and geodynamics induced by hydrocarbon production by summarizing the published case studies are considered. Changes in hydro-and gas dynamics affect changes in the geodynamics of the crust. Natural and technogenic changes in bowels of the Earth are usually entail tectonic movements and deformations of earth's surface, which is one of the important factors determining environmental changes and requiring mandatory consideration in engineering-geological surveys and exploitation of deposits. The approach is based on identified changes in hydrogeodinamics, stress-deformation state and seismic activity in areas of mineral resources of oil and gas fields. Negative geodynamic processes occurring on the territory of the Eastern Orenburg Region are identified. The analysis of the geodynamic state of the subsurface of the Eastern Orenburg Region is carried out. Based on the analysis, conclusions are made about possible causes of the geodynamic processes. An effective method for observing geodynamic processes using a seismological network is proposed and justified. A method of organizing a geodynamic polygon on a mineral field under development using a network of seismic stations has been developed.
\end{abstract}

\section{Introduction}

Geodynamics of the Southern Cis-Urals region are poorly understood, since the region is located inside the platform, and platform territories are considered to be geodynamically low-active and low-seismic. Until recently, it was believed that earthquakes rarely appear on the earth's surface by shocks of up to 4-5 Richter scale, and most of the oscillations recorded on the platform are only echoes of strong earthquakes from seismically active regions. The greatest attention was paid to areas with active mountain-folded structures. However, at present, it has become clear that the intra-platform territories are also mobile, especially in areas of tectonic disturbances and near folded areas.

Intensive oil and gas production in such large regions as Groningen gas field in Netherlands, War-Wink Field in USA, Romashkinskoye field and Orenburg oil and gas condensate field in Russia has disrupted natural environment [1-3], has significantly rebuilt hydro-gas-dynamic and geodynamic processes in the Earth's crust in the depth of more than

\footnotetext{
*Corresponding author: n_mu@mail.ru
} 
ten kilometers on an area of several tens thousands of square kilometers. The conditions for emergence of a number of environmental problems have been created, which significantly affect nature development and life quality of population in the region.

In large oil and gas regions, dangerous techno-natural processes develop in an upper part of the earth's crust. Such processes arise as a result of an unwanted rockmass response to human technological activity. As a result, seismic activity increases, a hydrogeodynamic regime is disrupted and subsidence of an Earth's surface is observed [4-7]. The basis for identifying reasons for increase in seismic activity during hydrocarbon production is based on the results of studies of hydro-gas-dynamic, geodynamic and geophysical processes and water systems dynamics in the regions of developed hydrocarbon fields.

Decrease in pressure in a water system that unites formation waters and surrounding aquifers of a hydrocarbon field, violates natural geodynamic state of the host rocks during hydrocarbons withdrawal and its increase during water injection. It also destabilize dynamic balance between water and a solid part of the Earth's crust [8].

\section{The description of the method and instruments}

To resolve the problems of geodynamic processes monitoring and forecasting in areas of oil $\&$ gas extraction is possible by means of complex approach method of geodynamic processes and seismic activity monitoring using geological and tectonic structure data of hydrocarbon deposit areas (HC). The method is developed by OSC URDiv RAS department of geoecology.

Oil \& gas bearing South Ural is taken as an area of anthropogenic changes in subsoil of $\mathrm{HC}$ areas research. South Ural is placed on the south-east of Eastern-European platform and includes Volga-Ural anteclise, Ural foredeep and northern edge of Caspian syneclise. The biggest in Europe Orenburg Oil\& Natural Gas Field (OONGF) (with productivity up to 40 billion $\mathrm{m}^{3}$ of gas in the year and many (more than 100) fields under development with productivity up to 20 million $\mathrm{m}^{3}$ are situated in this area. That's why in this area a strong anthropogenic influence on the geological environment is formed.

Seismic stations network "Oil\&Gas-seismicity" operates on the territory of intensive HC deposit areas development in South Ural in order to research the influence of technogenesis on the Earth's crust dynamics. The network "Oil\&Gas-seismicity" allows fulfill the monitoring of OONGF and close Oil fields seismic activity. Up to this moment the network consist of 10 seismic stations equipped by seismometers Guralp, CME, CM3KB and CM3-OC and digital seismic units Baikal, SDAS v 3.1 and UGRA.

The method of geodynamic monitoring by means of seismological network is created on the basis of fulfilled researches of geodynamic activity in the HC deposit development areas.

The complex system of geodynamic polygons comprises the following stages:

1. Creation of rarified seismic monitoring stations network ( 3 stations on $10000 \mathrm{~km}^{2}$ ) for detection of seismic active territories of the field or group of fields. Analysis and refinement of the territory geological structure;

2. Condensation of seismic stations network on seismic active territories;

3. Creation of the territory seismic activity map of the field and recommendations for geodynamic polygon creation;

4. Development of rarefied geodynamic polygons network location plan on the basis of geodesic monitoring only on the more seismic active areas with decreasing of the quantity of stations;

5. Complex monitoring of HC deposit developed area geodynamic processes, their analysis and issue of recommendations about increasing of safety work performance. 


\section{Results and discussions}

Using the example of the Southern Cis-Urals we have determined that hydrocarbon production has main effect on an upper part of the Earth's crust through a water system [9].

To date, anthropogenic influence on the surface of the Earth's crust in the process of searching and exploration of many oil \& gas fields significantly increased. The dynamics of ground waters and as a result the geodynamics of the Earth's crust [9] on the biggest part of South Ural are radically changed during the extraction of big volumes of hydrocarbon, penetrating to the large depth of the Earth by drilling test holes and production wells, frequently enveloping all sedimentary cover of the Earth's crust.

Over 45 years of the Orenburg oil and gas condensate field operation, located on an area of more than $2000 \mathrm{~km}^{2}$, more than 1.2 trillion $\mathrm{m}^{3}$ of hydrocarbon raw materials and about 30 million $\mathrm{m}^{3}$ of associated waters have been extracted. As a result, the pressure in a productive strata decreased from 20.6 MPa to 8.0 MPa and even below. The inflows of formation water into the gas reservoir go both laterally and vertically from below and from above. Since the start of Orenburg Field operation, over 39 million $\mathrm{m}^{3}$ of a water-methanol mixture and industrial runoff have been injected through injection wells of the field. The assumed stabilizing processes of a water-methanol mixture injection are unlikely to really affect geodynamic processes in an upper part of the Earth's crust due to their small volume in comparison with the total volumes of hydrocarbons and associated waters extracted from bowels.

According to our data, increased geodynamic and seismic activity stipulated by natural and anthropogenic reasons is registered in developed $\mathrm{HC}$ deposit areas. It is logically to understand the complex of anthropogenic and natural seismicity by anthropogenic - natural seismicity. Than anthropogenically stipulated seismic event is the release mechanism of accumulated in geological structures energy in the result of natural geodynamic processes. Anthropogenic - natural earthquakes may envelope big volumes of Earth's crust and have a big power.

At the present time, the influence of the humanity on the Earth's crust seismicity is multivariable. The influence is an extraction of solid, liquid and gaseous minerals, intake of underground waters and pumping of them into geological structures, blasting operations on the Earth's surface and subsoil, reservoir construction and other. We researched geodynamic processes and seismicity of the Earth's crust within oil \& gas production on the example of oil \& gas bearing South Ural, where the main zones of planetary-tectonic fissuring are marked [9].

At present, according to our research and data of "Gazprom dobycha Orenburg" Ltd, a negative hydrodynamic funnel with a capacity of 11-12 MPa in the center has formed in the Field water system. Its influence zone extends $20-30 \mathrm{~km}$ or more to the north and south from a gas contour (Fig. 1).

Volume of a hydrodynamic funnel is determined by quantity of extracted hydrocarbons and associated water minus water injected and penetrated into the reservoir from surrounding aquifers, taking into account the porosity and rocks fracturing. An estimate of the water amount penetrated into a gas condensate reservoir can be made using the formula of V. Shchelkachev [10]:

$$
V=\beta^{*} V_{w} * \Delta P
$$

where $V$ is a volume of formation water introduced into the reservoir, thousand $\mathrm{m}^{3} ; \beta$ is a coefficient of formation elastic capacity (Orenburg Field it is taken $2 * 10^{-4} \mathrm{MPa}^{-1}$ ); $V_{w}$ is water volume in the hydrodynamic funnel, thousand $\mathrm{m}^{3} ; \Delta P$ is decrease in reservoir pressure in a water system. 
Calculations for estimation using formula (1) showed that by 01.01.2014, with an average decrease in reservoir pressure by $4.2 \mathrm{MPa}$ since the beginning of field development, the water volume introduced into the reservoir, increased to 105 million $\mathrm{m}^{3}$. The gas volume extracted from pore-fractured space under reservoir conditions at a pressure of $16 \mathrm{MPa}$ and a temperature of $32^{\circ} \mathrm{C}$ is estimated to be about 4.9 billion $\mathrm{m}^{3}$. Consequently, the amount of formation water penetrated into the reservoir as of 01.01.2014 is only $2.1 \%$ of the recovered gas volume in reservoir conditions [11, 12].

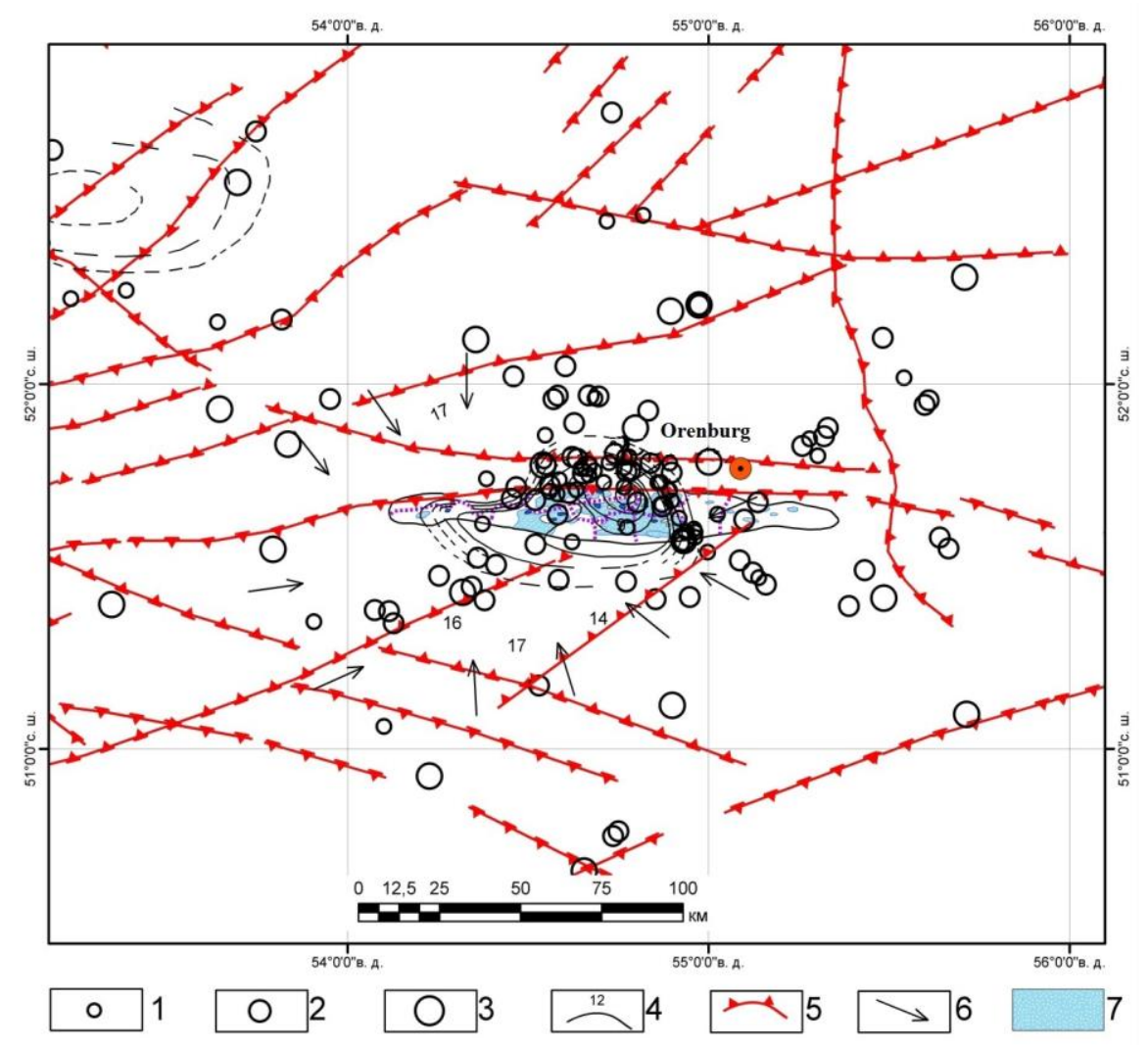

Fig. 1. Pressures distribution in formation waters of the Orenburg Oil and Gas Field, water-cut zones containing flooded wells, and seismic activity of the Field area as of 01.01.2017 (according to the materials of "VOLGOURALNIPIgaz" Ltd and the author's data)

1-3 - seismic events with according energy class: 1 (3.5-5.0), 2 (5.1-7.5) or 3 (7.6-11); 4 reservoir pressure isobars, MPa, 5 - structure-forming faults; 6 - direction of water flow into water pressure system; 7 - wells watering zones.

With decrease in pressure of a water system of hydrocarbon deposits, there is a drop of counteraction to lithostatic subsidence of overlying rocks and to swelling of low-permeable deposit's base under retained action of high pressure in a level deeper than the aquifers depth.

This indicates the dominant role of a water system in stress-strain state formation, geodynamic and seismic activity of the Earth's crust in the regions of hydrocarbon production. The greatest seismic activity is observed in the territories with the greatest drop in reservoir pressure and in the regions faults which spread outside the fields.

Seismic activity can be largely provoked and intensified by the presence of man-made objects (quarries, mines, reservoirs, large industrial enterprises, overburden dumps, slag and sludge storage facilities) and technological activities of enterprises (quarrying, excavation 
of mine workings, production of drilling and blasting operations, etc. etc.). Analysis of historical data and instrumental observations shows that geodynamic processes in the East of the Orenburg region occur continuously.

Seismic stations of the Republic of Kazakhstan, stations of the geophysical network of the Russian Academy of Sciences and stations of the OFITS UB RAS in the Eastern Orenburg region record a significant number of seismic events with a magnitude of up to 2.5 units and more. So in 2019, 220 seismic events were recorded.

We have carried out an analysis of geodynamic phenomena in the Eastern part of the Orenburg region, coinciding with blasting operations at the mines of the mining companies "Gaysky Mining and Processing Plant" and JSC "ORMET". It follows from the above analysis that $74.5 \%$ of geodynamic processes are provoked by blasting operations in the mines of mining enterprises, mostly in mines.

The mass of the explosive used in an explosion in a quarry is, as a rule, 1-2 orders of magnitude greater than in a mine. Nevertheless, out of 164 geodynamic phenomena that coincide with explosions in quarries and mines, blasting operations in mines account for 148 or $90.2 \%$ of the phenomena. Apparently, this is due to the fact that the energy of the explosion in the quarry is aimed at loosening and ejection of rocks and mostly goes into the atmosphere, while the energy in the underground mine, on the contrary, is mostly absorbed by the earth's crust.

The speed of propagation of longitudinal seismic waves in rocks can vary, depending on their density, from $0.3-0.8 \mathrm{~km} / \mathrm{s}$ in loose sedimentary geological deposits with a density of $1.2-1.7 \mathrm{~g} / \mathrm{cm}^{3}$ to $7.8-8.2 \mathrm{~km} / \mathrm{s}$ in ultrabasic metamorphic rocks with a density of $2.9-3.3$ $\mathrm{g} / \mathrm{cm}^{3}$.

The heterogeneity and wide scatter of the recorded epicenters of seismic events from the mines, where the explosions coincided in time with them, can be explained by the complex geological structure of the Eastern Orenburg region with numerous tectonic faults and the great remoteness (more than $200 \mathrm{~km}$ ) of the seismic station from the place of events.

For a more detailed study of all occurring seismic events and assessment of the level of natural and man-made seismic activity, the Orenburg Federal Research Center of the Ural Branch of the Russian Academy of Sciences is working to create a network of seismic stations in the area of the Gaysky urban district.

Observing geodynamic activity will make it possible to identify and assess the level of natural and man-made seismicity, make a decision on further geodynamic monitoring of the territory, and make a preliminary assessment of the impact of seismic activity of the territory on the occurrence of emergency situations.

The performed analysis revealed anomalous seismic activity in the territory of the Gaysky urban district and the Novoorsky district of South Ural and indicates the need to monitor the geodynamic processes occurring in the area of the Gaysky Mining and Processing Plant and conduct scientific research of the geodynamic state of the subsoil and assess the level of geoecological risks of the territory with the revealed increased seismic activity.

In the future, it is planned to conduct research work on the previously proposed algorithm:

1. Creation of three to four seismic stations and monitoring of seismic activity in the study area.

2. Accumulation of data on seismic activity, their analysis taking into account technogenic phenomena.

3. Zoning of the territory according to the level of geodynamic activity.

4. Thickening of the seismic network in areas with high geodynamic activity.

5. Based on the monitoring results, the identification of seismically active blocks on geological and tectonic maps. 
6. Observation of deformations of the earth's surface in geodynamically active areas.

7. Determination of the integral indicator of geodynamic risk and its threshold value in the territories of mining enterprises and the Iriklinskaya hydroelectric power station.

8. Analysis of the integral indicator of geodynamic risk with its threshold value and when it is exceeded, the development of recommendations for adjusting the mode of production activities of industrial and mining enterprises.

\section{Conclusions}

1. In the Southern Cis-Urals, with intensive exploitation of oil and gas fields, the decrease in reservoir pressure reaches $12 \mathrm{MPa}$ and more. As a result, the directions and velocities of a groundwater movement change, as well as the filtration-capacitive properties of the surrounding geological environment, its geodynamic balance, so man-made and natural earthquakes are intensified.

2. A multiple increase in seismic activity of the Earth's crust in the regions of developed hydrocarbon fields has been established. Its maximum activity is spatially confined to hydrodynamic craters, concentrating in the zones of the greatest drop in reservoir pressure and tectonic disturbances.

3. Monitoring of natural and man-made seismicity makes it possible to clarify the geological structure of an upper part of the Earth's crust, including fault structures position and to identify areas of technogenic pressure disturbances in a groundwater system.

4. Negative geodynamic processes occurring on the territory of the Eastern Orenburg Region are identified. Conclusions are made about possible causes of the geodynamic processes. $74.5 \%$ of geodynamic processes are provoked by blasting operations in the mines of mining enterprises, mostly in mines.

\section{References}

1. V. Adushkin, V. Rodionov, S. Turuntaev, A. Yudin. Oilfield Rev., 12 (2000)

2. M. Hubbert, W. Rubey. Geol. Soc. Am. Bull.,70 (1959)

3. W. Pennington, S. Davis, S. Carl-son, J. Dupree, T. Ewing. Bull. Seism. Soc. Am., 76 (1986)

4. S. Gibowicz, S. Lasocki. Adv. Geophys., 44 (2001)

5. M. Baker, D. Doser, M. Luo, Bulletin - West Texas Geol. Soc., 31 (1991)

6. Van Eijs, R.M.H.E., Mulders, F.M.M., M. Nepveu, C. Kenter, B. Scheffers. Eng. Geol., 84 (2006).

7. D. Amorese, J. Grasso, L. Plotnikova, B. Nurtaev, R. Bossu. Bull. Seism. Soc. Am., 85 (1995)

8. J. Suckale. Adv Geophys., 51 (2009)

9. A. Tsviak, M. Nesterenko, A. Nesterenko. ISEES 2018

10. V. Shelkachev, B. Lapuk. Underground hydraulics: textbook (2001)

11. V. Vlackij, M. Nesterenko, A. Tsviak. Ekologiya i razvitie obshchestva, 18 (2016)

12. M. Nesterenko, Yu. Nesterenko, A. Sokolov. Geodynamic processes in the developed hydrocarbon fields (on the example of the Southern Cis-Urals) (2015) 